\title{
TCGA Pan-Cancer Genomic Analysis of Alternative Lengthening of Telomeres (ALT) Related Genes
}

\author{
Isaac Armendáriz-Castillo ${ }^{1}\left(\mathbb{D}\right.$, Andrés López-Cortés ${ }^{1,2}{ }^{\mathbb{D}}$, Jennyfer García-Cárdenas ${ }^{1} \mathbb{C}$, \\ Patricia Guevara-Ramírez ${ }^{1}$, Paola E. Leone ${ }^{1}{ }^{\mathbb{D}}$, Andy Pérez-Villa ${ }^{1}{ }^{(0)}$, Verónica Yumiceba ${ }^{1}$ (D), \\ Ana K. Zambrano ${ }^{1}$ (D), Santiago Guerrero ${ }^{1,2, *}$ and César Paz-y-Miño ${ }^{1, * \mathbb{D}}$ \\ 1 Centro de Investigación Genética y Genómica, Facultad de Ciencias de la Salud Eugenio Espejo, Universidad \\ UTE, 170129 Quito, Ecuador; fabian.armendariz@ute.edu.ec (I.A.-C.); aalc84@gmail.com (A.L.-C.); \\ jennyfer.garcia@ute.edu.ec (J.G.-C.); alexandra.guevara@ute.edu.ec (P.G.-R.); paola.leone@ute.edu.ec (P.E.L.); \\ andy.perez@ute.edu.ec (A.P.-V.); veronica.yumiceba@ute.edu.ec (V.Y.); anak.zambrano@ute.edu.ec (A.K.Z.) \\ 2 Latin American Network for Implementation and Validation of Clinical Pharmacogenomics \\ Guidelines (RELIVAF-CYTED), Madrid, Spain \\ * Correspondence: sxguerrero@gmail.com (S.G.); cesar.pazymino@ute.edu.ec (C.P.-y.-M.)
}

Received: 29 May 2020; Accepted: 15 July 2020; Published: 21 July 2020

check for updates

\begin{abstract}
Telomere maintenance mechanisms (TMM) are used by cancer cells to avoid apoptosis, 85-90\% reactivate telomerase, while $10-15 \%$ use the alternative lengthening of telomeres (ALT). Due to anti-telomerase-based treatments, some tumors switch from a telomerase-dependent mechanism to ALT; in fact, the co-existence between both mechanisms has been observed in some cancers. Although different elements in the ALT pathway are uncovered, some molecular mechanisms are still poorly understood. Therefore, with the aim to identify potential molecular markers for the study of ALT, we combined in silico approaches in a 411 telomere maintenance gene set. As a consequence, we conducted a genomic analysis of these genes in 31 Pan-Cancer Atlas studies from The Cancer Genome Atlas and found 325,936 genomic alterations; from which, we identified 20 genes highly mutated in the cancer studies. Finally, we made a protein-protein interaction network and enrichment analysis to observe the main pathways of these genes and discuss their role in ALT-related processes, like homologous recombination and homology directed repair. Overall, due to the lack of understanding of the molecular mechanisms of ALT cancers, we proposed a group of genes, which after ex vivo validations, could represent new potential therapeutic markers in the study of ALT.
\end{abstract}

Keywords: telomeres; cancer; ALT; in silico

\section{Introduction}

Telomeres are nucleoprotein complexes that consist of a tandem 5'-TTAGGG-3' sequence and protect the ends of eukaryotic chromosomes, preventing DNA damage response (DDR), end-to-end fusions and genomic instability [1]. Telomeric DNA ranges from 3 to $15 \mathrm{~Kb}$ in humans, leaving a G-rich 3'-single-strand extended beyond the complementary chain, usually called the G-overhang [1,2]. To avoid the end-protection problem due to the overhang chain, the G-tail folds into itself, invading the double-stranded telomeric DNA, forming a lasso-like structure called the t-loop [3], which is protected by a six protein complex called shelterin [4], essential for telomere replication and regulation [2,3]. The shelterin complex is composed of the telomeric repeat binding factors 1 and 2 (TRF1 and TRF2), which interact with the telomeric double-stranded DNA and the protection of telomeres 1 (POT1) that bind to the single-stranded DNA [5].

TRF1 and TRF2 associate directly with the TRF1 interacting nuclear factor 2 (TINF2 or TIN2), which stabilizes their bond with the telomere; the shelterin complex subunit, the telomerase recruiting 
factor (ACD or TPP1) and the TRF2 interacting protein (TRF2IP or RAP1) complete the complex that protects and regulates telomere structure, DNA damage response and lengthening [5]. Nonetheless, with each round of the cell cycle, telomeres lose about 200 nucleotides; and eventually, this shortening leads to senescence or apoptosis [6].

To avoid senescence or apoptosis caused by telomere shortening, cancer cells take advantage of a set of mechanisms known as Telomere Maintenance Mechanisms (TMM), which include: telomerase reactivation and the alternative lengthening of telomeres (ALT) [1,6]. A high proportion of tumors reactivate the expression of telomerase to maintain its chromosomal ends, while $10-15 \%$ of human cancers use the ALT pathway [7]. ALT is frequently detected in tumors of mesenchymal or neuroephitelial origin [8], but there have been reports of the ALT mechanism detected in a fraction of epithelial tumors like: breast, skin, ovarian, uterus and gastric, among others [3,9].

ALT-positive (ALT+) cells display a characteristic phenotype. Telomeric DNA in ALT+ cells is constantly elongating, commonly depending on break-induced replication (BIR) processes, which are part of the homologous recombination (HR) pathway or homology-directed repair (HDR) mechanism [10,11]. ALT+ cells also show heterogenous telomere length, abundant extrachromosomal repeats (ECTRs), telomere sister chromatid exchange (T-SCE) [12] and high levels of extrachromosomal single-stranded telomeric DNA known as c-circles, which are molecular markers for ALT+ cells detection [13].

The main characteristic of ALT+ telomeres is the interaction with promyelocytic leukemia (PML) proteins, which altogether are believed to function as platforms for telomere recombination and are called ALT-associated PML bodies (APBs) [12,14]. In fact, there is evidence that the disruption of APBs blocks the ALT mechanism [12].

Although, many ALT-related genomic alterations have been resolved, such as the loss of function of ATRX, DAXX, H3F3A, or the BIR-related pathways dependent or independent of RAD51 and $R A D 52[1,7,10,15]$, the molecular basis through which ALT occurs remains elusive and poorly understood [7]

Many anti-telomerase-based cancer therapies are believed to cause the switching in some tumors from telomerase to ALT $[3,16]$. Indeed, the co-existence of both telomerase-dependent and ALT mechanisms have been reported in different cancer types [3,17]. This evidence sheds light on ALT as a potential target for therapy, because of the poor prognosis associated with these cancer types $[1,7,18]$. Different drugs have been tested in the last years to target ALT+ cells, however, most of them have been unsuccessful and still are in phases $1 / 2$ of clinical trials [1,12].

Even though several ALT-associated factors have been uncovered, the pathway activation, regulation and functioning require further investigation [12]. Therefore, the identification of new potential molecular markers would be of enormous importance in the future design of new strategies for the detection and treatment of ALT+ cancers.

To fulfill this need, we evaluated the genomic alterations of 411 telomere maintenance (TM) genes in 9282 samples from 31 Pan-Cancer Atlas (PCA) studies and applied different in silico approaches with the aim to identify and propose a set of genes which after ex-vivo validations could be used as potential molecular markers to improve the study of the ALT pathway.

\section{Materials and Methods}

\subsection{Gene Set}

TelNet (http://www.cancertelsys.org/telnet/) is a database that groups more than 2000 human TM genes. All genes are annotated according to their classification of TMM, TM function and a significance score given by the evidence of gene function in telomeres [19]. The database shows the role of each gene in ALT and telomerase-mediated mechanisms and classifies them as enhancers, repressors or ambiguous (when their role in the ALT mechanism is defined but their activity is not yet clear). Therefore, the TelNet database was downloaded and manually filtered in order to select a set of genes 
that were associated with ALT activities as: enhancers, repressors and ambiguous. Consequently, a total of 411 TM genes were selected for the study.

\subsection{Genomic Alterations}

Genomic alterations (CNV amplification, CNV deep deletion, in-frame mutation, truncating mutation, missense mutation, fusions, mRNA up and down regulation) were analyzed in the cBio Portal (http://www.cbioportal.org/) [20,21]. A total of 9282 samples were selected from 31 Pan-Cancer Atlas (PCA) studies from The Cancer Genome Atlas (TCGA) (LAML, ACC, BLCA, LGG, BRCA, CESC, CHOL, COAD, DLBC, ESCA, GBM, HNSC, KIRC, KIRP, LIHC, LUAD, LUSC, MESO, OV, PAAD, PCPG, PRAD, SARC, SKCM, STAD, TGCT, THYM, THCA, UCS, UCEC and UVM) [22-31]. The frequency means of genomic alterations were compared with a Bonferroni correction test $(p<0.05)$ by using SPSS Statistics Software (IBM Corp., Armonk, NY, USA).

\subsection{Prevalence of the ALT Mechanism in Different Cancer Types}

The ALT mechanism is frequent in tumors of mesenchymal origin; however, ALT positive cells have been observed in epithelial tumors. Therefore, the prevalence of the ALT mechanism in the different TCGA cancer studies was reported as part of this study and the tumors were classified in three different categories: frequent ALT tumors, rare ALT tumors and not reported (for tumors without evidence of ALT+ cells). Additionally, the first quartile of the most altered genes from the PCA studies was classified in each of the categories described earlier.

\subsection{Protein-Protein Interaction Network}

In order to predict the interactions among the ALT-related proteins, the STRING database (https://string-db.org/) was used. An interaction score of 0.9 (highest confidence) was set in the system configuration $[32,33]$ and the most significant signaling pathways $(p<0.001)$ related to ALT were selected and differentiated by colors in the network.

Break-induced replication (BIR) is a main process used by ALT+ cells to extend their telomeres [34], therefore, the gene set of the homologous recombination pathway was downloaded from the Kyoto Encyclopedia of Genes and Genomes (KEGG) [35] and an interaction network with the ALT-related genes selected in this study was constructed with the aid of the STRING database; an interaction score of 0.9 (highest confidence) was set in the system configuration. Proteins interactions were determined according to database curation, experimental determination and co-expression [36].

\subsection{Gene Set Enrichment Analysis}

An enrichment analysis was made using the g:Profiler tool (https://biit.cs.ut.ee/gprofiler/gost) [37]. The most significant pathways were selected after Benjamini-Hochberg and False Discovery Rate (FDR) corrections $(p<0.001)$, based on Gene Ontology (GO), Molecular Function (MF), Biological Process (BP), KEGG, REACTOME database and Human Phenotype (HP).

\section{Results}

\subsection{Role of the TM Gene Set in the ALT Mechanism}

The 411 genes from the TelNet database [19] (Table S1) were filtered according to their activity in ALT. Figure 1 shows a Venn diagram with the reported TMM activity of the gene set; 77 genes were classified as enhancers of ALT, 1 as repressor and 333 had ambiguous activity. 


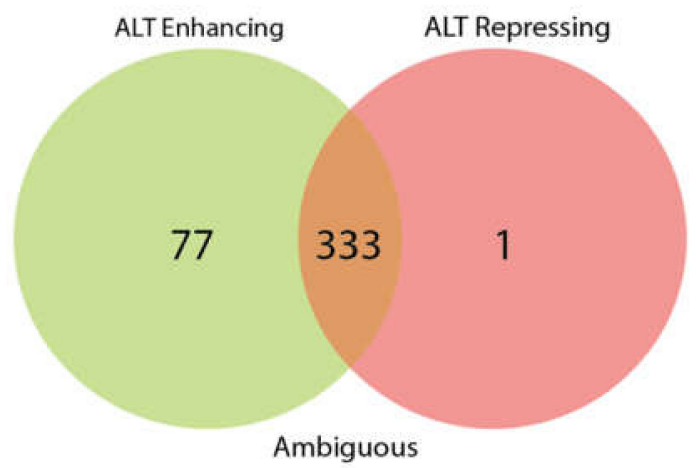

Figure 1. Role of the gene set in the ALT mechanism. The 411 gene set selected for this study was filtered according of their alternative lengthening of telomeres (ALT) activity in the TelNet database and classified as enhancers, repressors or ambiguous.

\subsection{Genomic Alterations}

To address the genomic alterations of ALT-related genes, these were analyzed in the cBioPortal [20,21] by selecting 9282 samples from 31 PCA studies from TCGA [22-31] (Table 1).

Table 1. List of The Cancer Genome Atlas (TCGA) Pan-Cancer Studies with the number of individuals.

\begin{tabular}{|c|c|c|c|}
\hline TCGA Study & $n$ & TCGA Study & $n$ \\
\hline Acute Myeloid Leukemia (LAML) & 165 & Lung Squamous Cell Carcinoma (LUSC) & 466 \\
\hline Adrenocortical Carcinoma (ACC) & 76 & Mesothelioma (MESO) & 82 \\
\hline Bladder Urothelial Carcinoma (BLCA) & 402 & Ovarian Serous Cystadenocarcinoma (OV) & 201 \\
\hline Brain Lower Grade Glioma (LGG) & 507 & Pancreatic Adenocarcinoma (PAAD) & 168 \\
\hline Breast Invasive Carcinoma (BRCA) & 994 & Pheocromocytoma and Paraganlioma (PCPG) & 161 \\
\hline Cervical Squamous Cell Carcinoma (CESC) & 275 & Prostate Adenocarcinoma (PRAD) & 488 \\
\hline Cholangiocarcinoma $(\mathrm{CHOL})$ & 36 & Sarcoma (SARC) & 251 \\
\hline Colorectal Adenocarcinoma (COAD) & 524 & Skin Cutaneous Melanoma (SKCM) & 363 \\
\hline Diffuse Large B-cell Lymphoma (DLBC) & 39 & Stomach Adenocarcinoma (STAD) & 407 \\
\hline Esophageal Adenocarcinoma (ESCA) & 181 & Testicular Germ Cell Tumors (TGCT) & 144 \\
\hline Glioblastoma Multiforme (GBM) & 145 & Thymoma (THYM) & 119 \\
\hline $\begin{array}{l}\text { Head and Neck Squamous Cell Carcinoma } \\
\text { (HNSC) }\end{array}$ & 488 & Thyroid Carcinoma (THCA) & 480 \\
\hline Kidney Renal Clear Cell Carcinoma (KIRC) & 352 & Uterine Carcinosarcoma (UCS) & 56 \\
\hline $\begin{array}{c}\text { Kidney Renal Papillary Cell Carcinoma } \\
\text { (KIRP) }\end{array}$ & 274 & $\begin{array}{c}\text { Uterine Corpus Endometrial Carcinoma } \\
\text { (UCEC) }\end{array}$ & 507 \\
\hline Liver Hepatocellular Carcinoma (LIHC) & 348 & Uveal Melanoma (UVM) & 80 \\
\hline Lung Adenocarcinoma (LUAD) & 503 & & \\
\hline
\end{tabular}

A total of 325,936 genomic alterations were identified (Table S2) and a pie chart with the most frequent alterations was constructed after all values were normalized by the number of samples. Figure 2a shows mRNA upregulation at the top with $65.8 \%$, followed by mRNA downregulation $(10.7 \%)$, copy number alterations (CNA): amplifications $(9.6 \%)$, missense mutation (putative passenger) with $7.2 \%$, deep deletion (3.1\%) and truncating mutations and fusion genes with less than $2 \%$.

Finally, to better understand the implication of ALT-related genes in cancer progression, from primary tumors to metastasis, we analyzed the genomic alterations in each cancer stage (Figure 2b) (Table S3). However, no significant difference was observed after a Bonferroni correction test $(p>0.01)$. As a result, it can be inferred that TM genes alterations and the ALT pathway across different types of tumors are not dependent on cancer staging. 
(a)

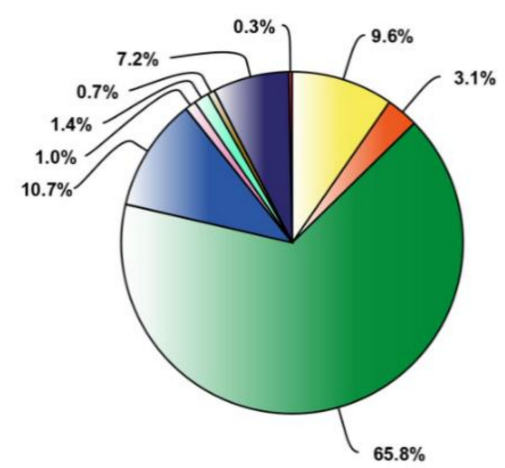

(b)

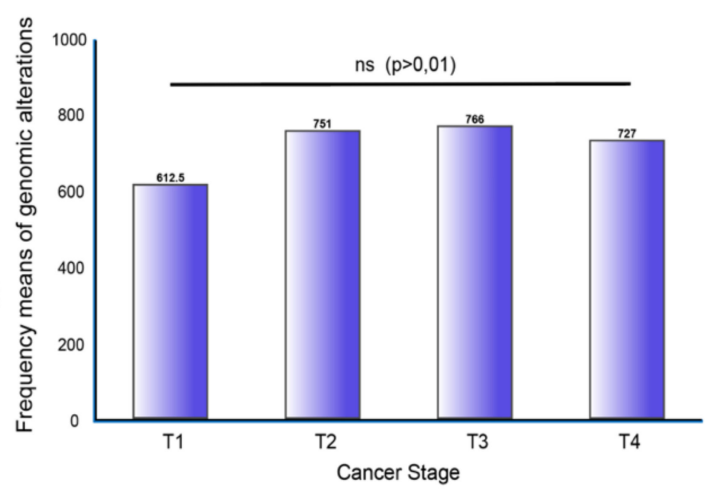

Figure 2. Genomic alterations. (a) Percentage of genomic alterations of 411 ALT-related genes distributed in the 31 PCA studies. (b) Frequency means of genomic alterations of the 411 genes in different cancer stages; no significant difference was observed after Bonferroni correction test $(p>0.01)$.

All values were normalized by the number of samples in each stage.

\subsection{TM Genes Validation and TCGA Pan-Cancer Studies Frequencies}

The gene set and each TCGA study were ordered by the highest frequency mean of genomic alterations to the lowest (Table S4). To narrow down our analysis, the first-quartile of genes $(n=103)$ was selected for further analysis and the highest frequencies of alterations for the 31 PCA studies were: UCS (56.054), OV (53.194), UCEC (49.387), ESCA (47.088), BLCA (44.883), ACC (44.658), SKCM (44.620), LUSC (43.822), STAD (43.005), BRCA (42.068), LUAD (40.942), CESC (40.116), COAD (39.038), SARC (37.418), LIHC (37.353), DLBC (37.256), HNSC (36.381), CHOL (35.444), PAAD (33.256), MESO (30.634), UVM (30.225), GBM (29.366), TGCT (29.132), KIRP (28.708), PRAD (28.258), LGG (27.387), PCPG (26.292), KIRC (24.168), LAML (21.255), THYM (20.185), and THCA (19.319) (Figure 3a).

To further identify which genes displayed abnormal values of genomic alterations in the 31 PCA studies, a boxplot with these frequencies was constructed for the 411 ALT-related genes (Figure 2b). Hence, after boxplot analysis, 20 genes showed an unusual value of genomic alterations; these were selected and proposed as candidate genes to be studied in the ALT pathway: TP53 (12.370), RAD21 (7.529), SENP5 (7.179), UBR5 (6.897), NSMCE2 (6.779), MCPH1 (6.332), PRKDC (6.091), RFC4 (5.662), RECQL4 (5.656), NBN (5.587), FBH1 (5.239), RAD1 (5.221), CCT5 (5.126), LRATD2 (5.013), RAD54B (4.969), ATR (4.940), SMG7 (4.888), TERF1 (4.817), ATF6 (4.778), and ARID1A (4.357).

Then, to obtain insights of the most altered genes in the PCA studies, additional boxplots were constructed (Figure 3c), along with the alteration frequencies of the 411 genes and the first quartile of the PCA studies with the highest means of genomic alterations (UCS, OV, UCEC, ESCA, BLCA, ACC, SKCM, LUSC and STAD). On this basis, the following genes were identified to be highly altered in more than one of the nine types of tumors: TP53 (9), UBR5 (8), RAD21 (6), SENP5 (6), NSMCE2 (5), RFC4 (5), MCPH1 (4), RECQL4 (4), ARID1A (3), CCT5 (3), LRATD2 (3), and RAD1 (3).

Finally, to elucidate which genomic alteration is most frequently observed across the 31 PCA studies, an oncoprint with the percentage of each alteration is shown for the first-quartile of genes (Figure 3d). As expected, mRNA upregulation is the most common alteration in the gene set, with certain exceptions where amplifications, mRNA downregulation and truncating mutations, appear most frequently. 
(a)

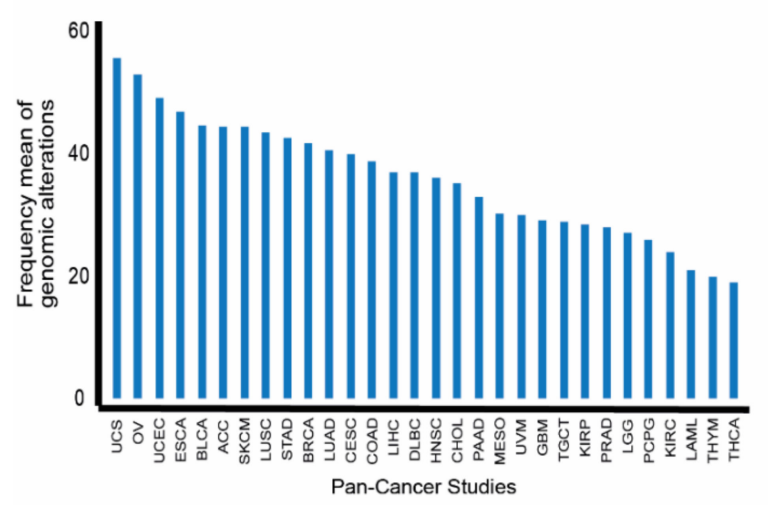

(b)

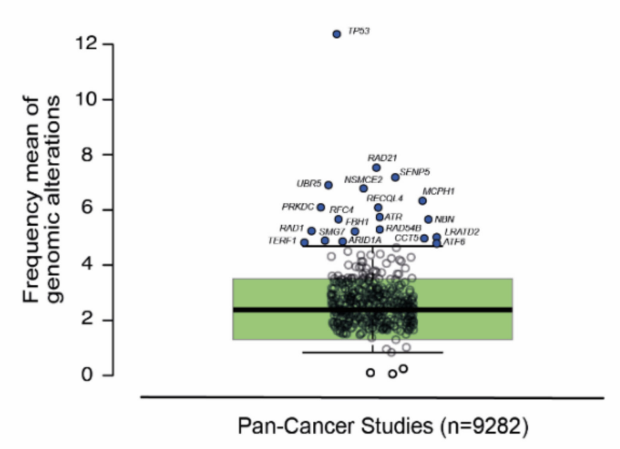

(c)

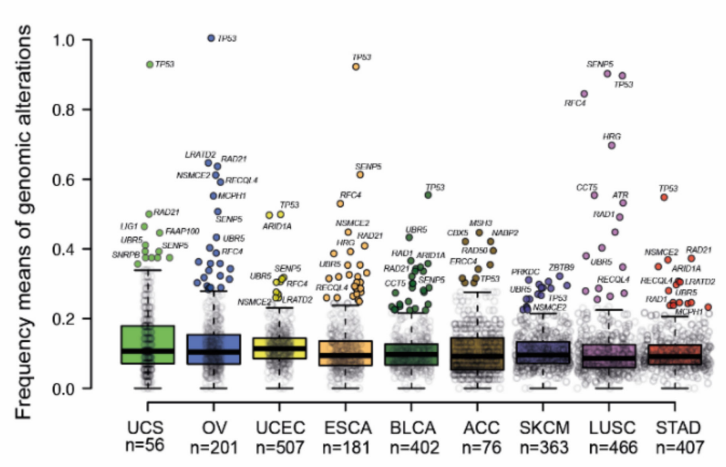

(d)

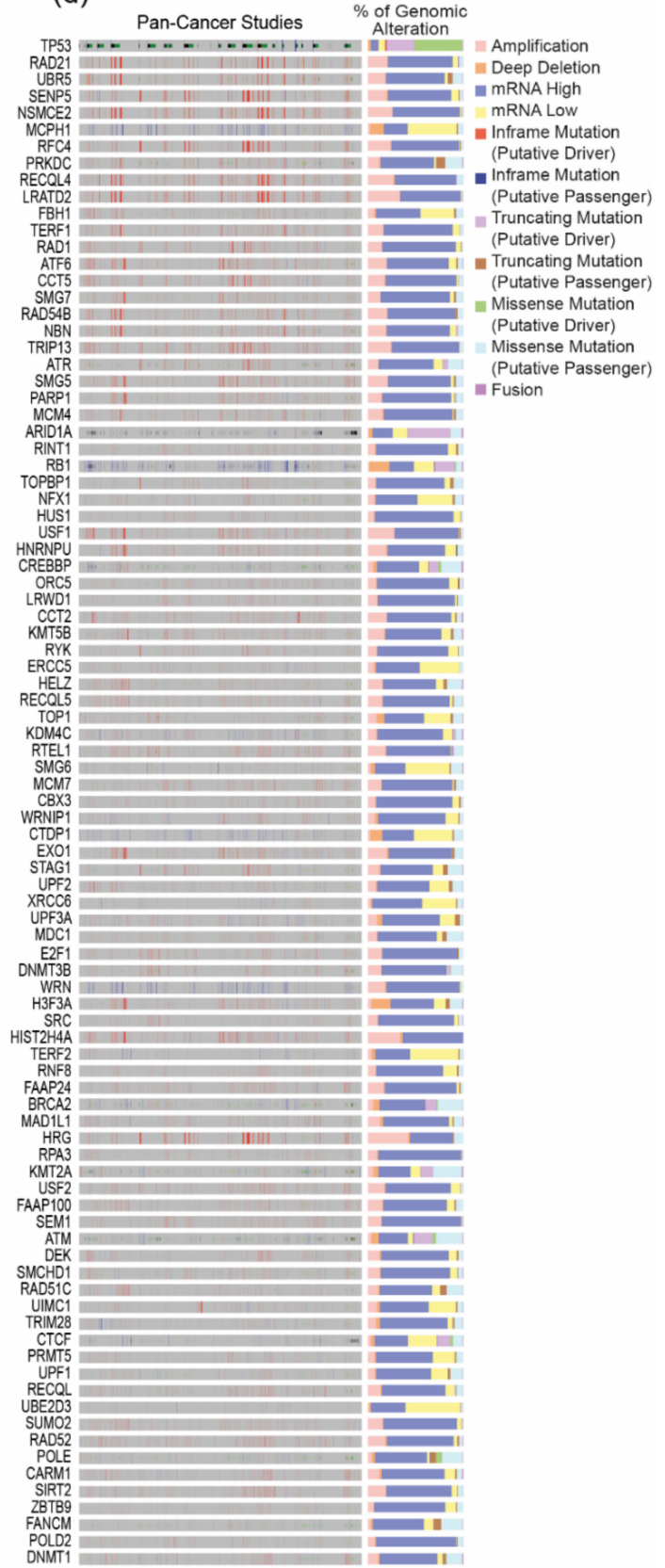

Figure 3. Top altered cancers and oncoprint. (a) Shows the most altered cancers according to the frequency means of genomic alterations of the 411 genes previously normalized by the number of samples in each PCA study. (b) Shows a boxplot with frequency means of genomic alterations of the 411 genes in all the 31 PCA studies; 20 genes were identified as highly altered and are represented in the blue dots. (c) Shows boxplots of the 411 genes with each of the first quartiles of the most altered PCA studies. The unusual altered genes are represented in color dots per each cancer study. (d) Shows the oncoprint of the most altered genes across the PCA studies, with the individual genomic alteration's profile of each gene marked in different colors. 


\subsection{Prevalence of the ALT Mechanism in the TCGA PanCancer tumors}

The presence of ALT in tumors across the 31 PCA studies have been analyzed and classified in three different categories: ALT frequent tumors, for cancers with ALT prevalence above the mean, ALT rare tumors, for cancers with prevalence below the mean, and tumors with no reports of the presence of ALT (Figure 4).

(a)

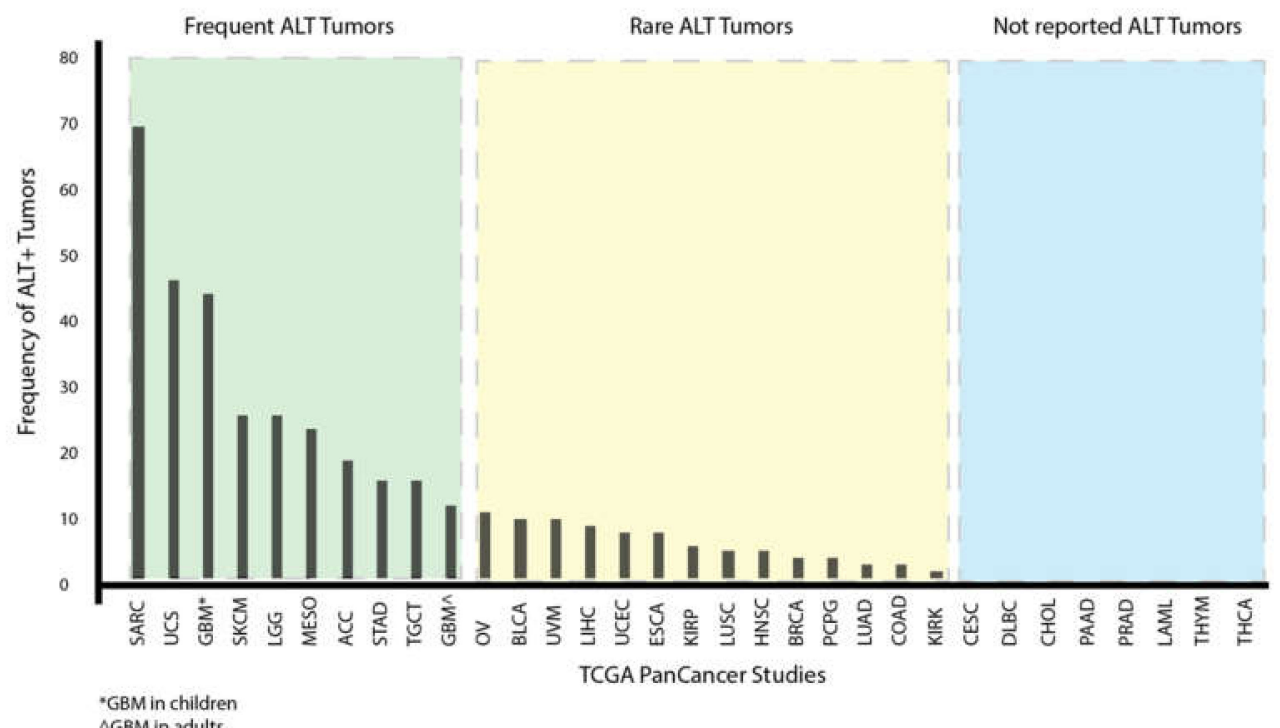

(b)

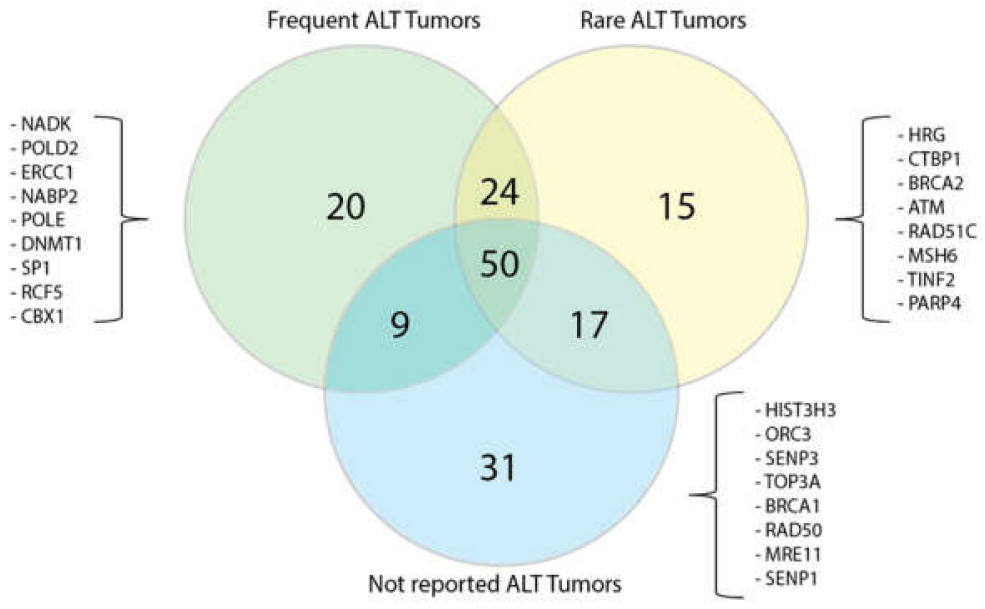

Figure 4. ALT mechanism prevalence in the PCA studies and its relationship with TM altered genes. (a) Shows the prevalence of the ALT mechanism in the 31 PCA studies; tumors were classified in three groups depending on the values above the mean as: Frequent ALT tumors, rare ALT tumors and not reported. (b) A Venn diagram showing the distribution of the most altered ALT-related genes in each ALT tumor group.

The 20 most altered genes across the 31 PCA studies are shown in Figure 3b. Furthermore, with the aim to classify the first-quartile of the highest mutated ALT-related genes $(n=103)$ in the PCA studies in each ALT tumor group, a Venn diagram was constructed (Figure 4b). As a result, a total of 20 genes was reported to be altered exclusively in the group of frequent ALT tumors, 15 genes in the rare ALT 
tumors group and 31 in the tumors with any reports of ALT. The overlapped areas in the Venn diagram show the number of altered genes shared among the groups.

As shown in Figure $4 b$, there are 24 genes shared between frequent and rare ALT tumors, and 50 genes are shared among the three groups; all 20 ALT-related genes $(100 \%)$ proposed in this study are highly mutated in the PCA studies (Figure $3 \mathrm{~b}$ ) and included in the 50 genes list; according to these results, the frequency of alterations of ALT-related genes is distributed among all cancer types. In contrast, any of the 20 ALT-related genes proposed are included in the 31 genes of the not-reported ALT tumors group. This result matches with our previous analysis from the boxplots and supports our selection of the 20 genes as potential markers for the study of ALT+ tumors. This analysis will allow to focus in a particular set of genes in future ex vivo validations in a selected group of tumors. A random representation of the most altered ALT-related genes for each group is shown in Figure $4 \mathrm{~b}$, and the complete list of the genes included in each ALT tumor type is shown in Table S6.

\subsection{Protein-protein interaction (PPi) Network and Enrichment Analysis}

PPi networks are useful resources to understand how proteins interact between them in the cell [38], hence, the STRING database [32] was used to observe the interactions of 103 proteins. By using an interaction score of highest confidence (0.9) [33], a network was constructed; additionally, the most significant pathways $(p<0.001)$ were selected and marked with different colors in the nodes (Figure 5a). As a result, $68 \%$ of the proteins in the network are essential for DNA binding; $59 \%$ for DNA metabolic process; $47 \%$ for DNA repair; $23 \%$ for telomere organization and maintenance; $12 \%$ for telomeric DNA binding; and 22\% are involved in DNA Double-Strand Break Repair, HDR and HDR through Homologous Recombination (HRR).

ALT+ tumors are known to use a BIR-related process for telomere extension. In consequence, the proteins from the HR pathway were analyzed with the aid of a PPi network with the 20 proteins selected as potential ALT targets in this study by following the same criteria used for constructing the network in Figure 5a. These interactions are shown in Figure 5b; as a consequence, 10 out of 20 proteins (RAD1, TERF1, RAD21, ATR, RFC4, TP53, PRKDC, CCT5, NSMCE2, and RECQL4) showed interactions with the BIR pathway; it is evident how the ALT-related proteins are co-expressing with the proteins from the BIR pathway; the relevance of the results will be discussed later.

In addition to the PPi networks, an enrichment analysis was made using g:Profiler [37] (Table S5); Figure 6a shows the enrichment map of 103 proteins. The most significant ALT-related pathways from the enrichment analysis were correlated in a CIRCOS plot with the genes that showed the highest means of genomic alterations in the boxplot analysis displayed in Figure 3b,c.

The CIRCOS plot shows the interaction of the ALT-related genes in DNA repair, binding and metabolic processes; but, at the same time, the interaction of genes RAD54B, NSMCE2, TERF1, SMG7, RECQL4, ATR, PRKDC, RAD1, RFC4, and NBN is observed in telomere organization, maintenance and binding, HR, HDR, and HRR.

As mentioned earlier, pathways like HR and HRR are BIR-related processes, which are mechanisms used by ALT cells for telomere extension. The influence of mRNA up and down regulation and amplifications, as the dominant genomic alterations of the genes involved in these pathways, will be discussed later. 


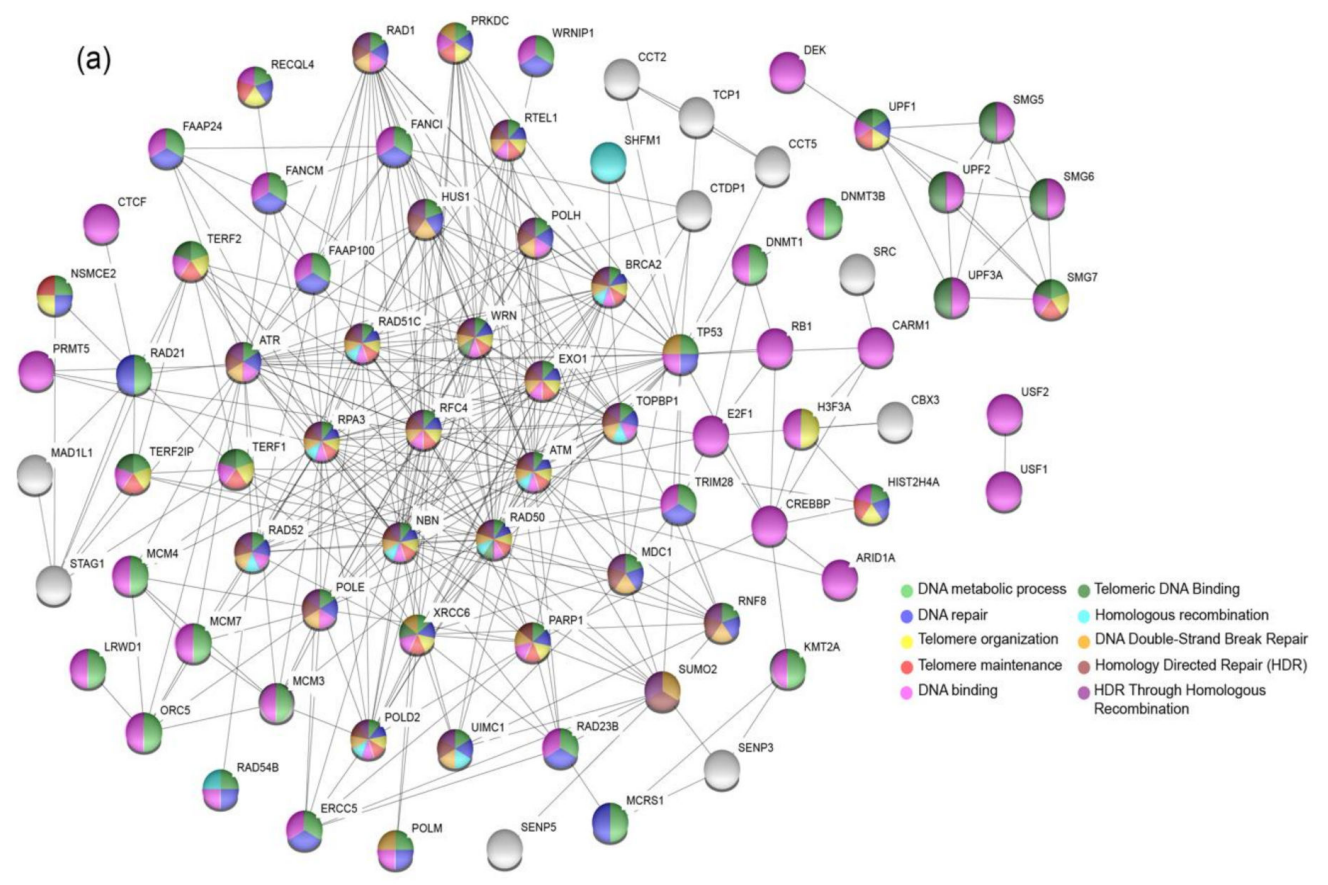

(b)

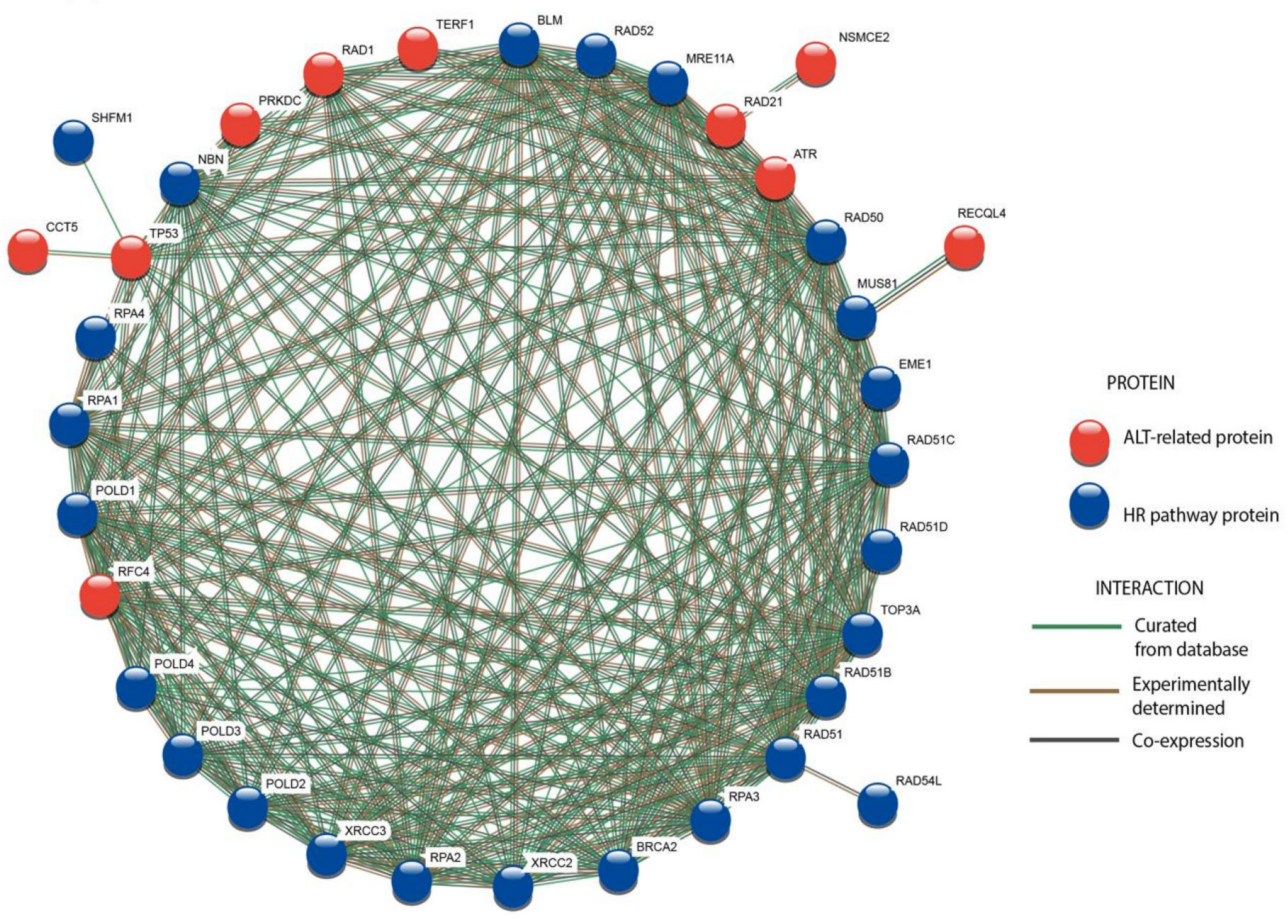

Figure 5. Protein-protein interaction (PPi) network and BIR-related pathway. (a) Shows the PPi network constructed in the STRING database; the most significant pathways are marked with different colors and represented in the nodes. (b) Shows the interaction network of the BIR-related pathway with the potential ALT targets selected in this study; protein interactions are classified according to database curation, experimental determination and co-expression. HR: Homologous Recombination. 


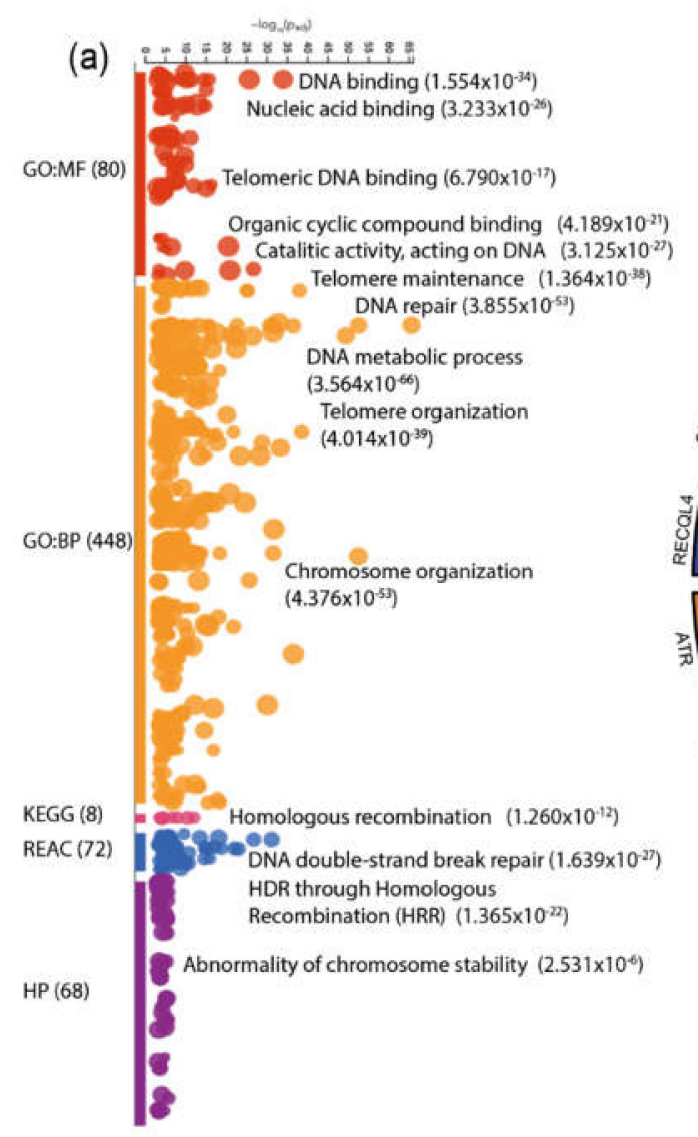

(b)

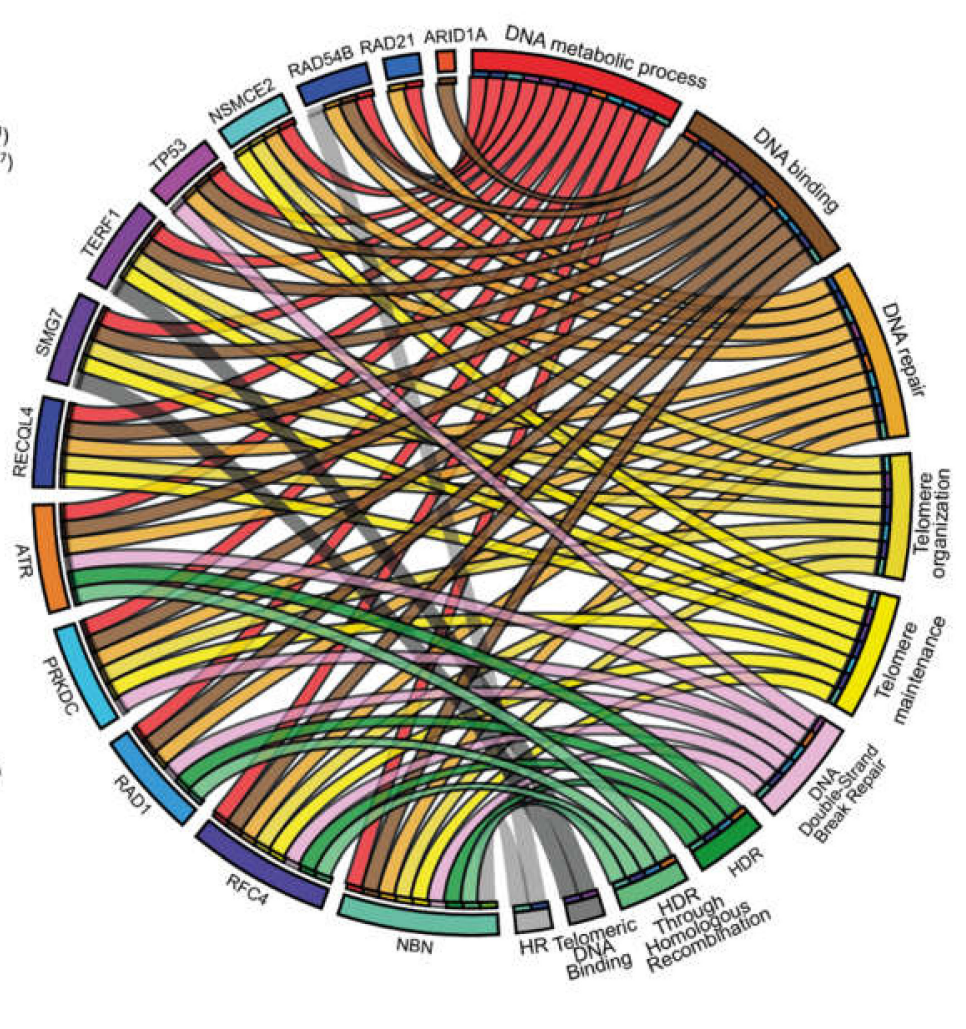

Figure 6. Enrichment analysis and protein-pathway correlation. (a) Shows the enrichment profile of 103 proteins; the most significant pathways for MF, BP, KEGG, Reactome, and HP are also shown next to the dots with its $p$-values. (b) Shows a CIRCOS plot corelating the genes with the highest means of alterations with its most significant pathways from the protein enrichment analysis. KEGG: Kyoto Encyclopedia of Genes and Genomes; HP: Human Phenotype. 


\section{Discussion}

$\mathrm{TM}$ is a crucial mechanism in the hallmarks of cancer for indefinite replicative potential, 10 to $15 \%$ of cancers do not depend on telomerase to maintain or extend its telomeres, instead, they use the ALT pathway [1]. In the last years, efforts to identify genes responsible for ALT progression have been made; so far, the main recurrent mutations identified in ALT+ cells are associated with ATRX/DAXX [1,15,39-41] RAD51/RAD52 BIR-related dependent or independent pathways [1,6,7] and histone H3.3 [42]. Nevertheless, the ALT pathway mechanism and the molecular basis underlying its expression, switching, detection, and treatment remain elusive [43,44]; therefore, we used simplistic OncoOmics and in-silico approaches to identify potential molecular markers to improve the study of the ALT mechanism.

Commonly, ALT is enriched in tumors of mesenchymal origin [45], however, there is evidence of the coexistence of telomerase-mediated and ALT mechanisms in some solid tumors. In fact, some anti-telomerase-based treatments have shown the capability of some cells to switch to ALT and escape death [6,15]. Figure 4a shows the frequency of the ALT mechanism in the different PCA studies according to what has been reported; so far, a variation of ALT+ tumors in different types of cancer has been observed, for example, for UCS, Lee et al. 2011 reported 40\% ALT+ cell lines [46], Heaphy et al. 2011 reported 7\% and Lee et al. 2018 reported 0\% [9]. On average, the following frequencies of ALT positive cell lines have been reported for the cancer types we found to have the highest frequencies of genomic alterations: OV 10\% [8,9], UCEC 7\% [8], ESCA 7\% [8,9], BLCA 9\% [8,9], ACC 18\% [8,41], SKCM 25\% [8,9,41,47], LUSC 4\% [8,9,41], STAD 15\% [9,41,48], and BRCA 3\% $[8,9,41]$. Nonetheless, due to the difficulty and lack of sensible diagnostic techniques for ALT+ tumors, those numbers may fluctuate $[12,49,50]$.

For our study, we found the highest frequency means of genomics alterations in the following PCA studies: UCS, OV, UCEC, ESCA, BLCA, ACC, SKCM, LUSC, STAD, and BRCA (Figure 3a). In addition, with the aid of boxplots, whose function is to show unusual values among a distribution of data, we identified 20 TM genes to be highly mutated among the 31 PCA studies (Figure 3b,c). This analysis, linked with the oncoprint showed in Figure 3d, correlates each altered gene with its main genomic alteration. As a result, TP53 is the most mutated gene in the majority of cases, which is not odd, due to the evidence of its function as a tumor suppressor. Nonetheless, it has been reported to be co-mutated with ATRX and histone H3.3 [51], and its deletions are heavily related with abnormal expression patterns of TERT (a well-known factor for ALT progression) [52].

Along with TP53, additional ALT-related genes were identified and proposed in this study as possible molecular targets that have been predicted by Lovejoy et al. 2012 as potential elements of the ALT pathway like UBR5, NSMCE2, RFC4, MCPH1, RECQL4, LRATD2, RAD1, RAD21, NBN, FBH1, RAD54B, ATR, SMG7, and TERF1 [42]. Likewise, according to Osterwald et al. 2015 and Chung et al. 2011, SENP5, NSMCE2, NBN, ATR, and TERF1 are involved in APBs formation [53,54], which are common elements of ALT+ cells for replication and extension of telomere ends [55]. Additionally, Dejardin et al. 2009 found NSMCE2, RFC4, CCT5, NBN, and TERF1 to be expressed in the telomeres of ALT+ cell lines [56].

Some of the genes proposed have been predicted to play an important role in ALT-related mechanisms; for instance: NSMCE2 recruitment is essential for APBs correct functioning [53], it is also part of the SMC5/SMC6 complex, in which inhibition is known to disrupt APBs formation [57]. NBN is part of the MRN complex (MRE11/RAD50/NBN) that helps in the assemble of the G-overhang in the lead telomeric strand [58]; additionally, it promotes the ALT mechanism by recruiting ATM to the telomeres, allowing the invasion of adjacent telomeric DNA to be used as a template for telomere extension [59].

Moreover, MCPH1 and ARID1A bind to the telomerase reverse transcriptase (hTERT) and regulate its expression [60]; the oncoprint in Figure $3 \mathrm{~d}$ shows these genes to be down-regulated across different cancer types, this can give an insight into their role in the switching from a telomerase-mediated extension to ALT. Another gene, LRATD2, is known to be upregulated in cells with short telomeres [61]. 
ATR is important in the assembly of the telomerase complex [62]. TERF1 is overexpressed in cells with long telomeres [63] and last but not least, RECQL4 is associated with shelterin proteins POT1, TRF1 and TRF2 in the formation and stability of the t-loop and its knockdown causes telomere disfunction, possibly favoring the start of the ALT mechanism [64,65].

According to the TelNet database, based on their predicted activity in the ALT pathway, TM genes are classified as enhancers, repressors or ambiguous [19] (Figure 1). Only NSMCE2, RFC4, NBN and ATR are recognized as enhancers, while, SENP5, UBR5, RAD21, MCPH1, RECQL4, ARID1A, CCT5, LRATD2, RAD1, FBH1, RAD54B, SMG7, and TERF1 are qualified as ambiguous. This highlights the importance of performing ex-vivo validations in the ALT-associated genes proposed in this study in order to improve the understanding of their role in the switching, progression or maintenance of ALT.

In addition to the 20 genes proposed for ex-vivo studies, we classified the genes based on their representation in the different types of ALT tumors proposed in Figure 4a. As shown in Figure 4b, there are genes altered only in determined groups of tumors. This can facilitate the development of future ex-vivo assays for specific types of cancers. For instance, the group of ALT-frequent tumors is represented by 20 genes like $N A D K$, a kinase predicted to be a negative regulator of telomerase [66] or ERCC1, which is implicated in the processing and extension of the G-overhang [58].

In order to understand the role of the proteins in ALT+ cells, a protein-protein interaction network was performed using STRING (Figure 5a). The most significant ALT-related pathways ( $p$ $<0.001$ ) were selected; 35\% of the 103 proteins analyzed were involved in telomere organization, maintenance and telomeric DNA binding, while 22\% are crucial for HR and HRR, which altogether with non-homologous end joining (NHEJ) have an important role in the mechanism by which ALT+ cells extend its telomeres $[67,68]$.

Break-induced replication (BIR) is a specialized form of HR [7]. BIR is a recombination-dependent process that reinitiates DNA replication using a DNA homologue template, leading to a conservative DNA synthesis [7]. ALT is known to use a BIR bifurcated pathway dependent or independent of RAD52, both pathways relying on the activation of POLD2 and POLD3 [7]; however, the basis underlying this mechanism is still unclear [69]. Hence, to observe the interaction of the proteins proposed as potential targets in the study of ALT, a PPi network with the proteins of the HR pathway was constructed; additionally, the interaction evidence among the proteins is shown according to database curation, experimental determination and co-expression. Figure $5 \mathrm{~b}$ shows that 10 of the proposed proteins are co-expressing (black lines) with the proteins in the HR pathway. All of the genes encoding for these proteins showed mRNA upregulation and amplification as their top genomic alterations in the oncoprint in Figure 3d. Gene amplifications can trigger the expression of genes in cancer cells, which could affect DNA repair and damage response [69,70], this could favor the upregulation of $H R$ and BIR-related pathways in ALT+ tumors; nonetheless, further experimentation would be required to validate this statement.

Moreover, we performed an enrichment analysis for 103 proteins using g:Profiler, which searches a collection of proteins with pathways, networks, GO, and cancer phenotypes [71]. The GO for molecular functions were DNA binding and telomeric DNA binding; the GO for biological process were telomere maintenance, DNA repair, telomere, and chromosome organization. The most significant KEGG signaling pathway was HR, and the most significant REACTOME pathways were DDSB repair and HRR. Finally, the human phenotype related to the proteins analyzed was abnormality of chromosome stability (Figure 6a).

Furthermore, we selected the proposed ALT-related genes in our study, the most significant pathways from the PPi and enrichment analysis and constructed a CIRCOS plot (Figure 6b) to observe the main pathways in which they are involved. As anticipated, most genes like RAD54B, NSMCE2, TERF1, SMG7, RECQL4, ATR, PRKDC, RAD1, RFC4, and NBN are directly involved in pathways like DDSB, HR, HDR, and HRR among others, which are ALT-related processes. The enrichment analysis concluded that genes related to HR are upregulated and amplified in the PCA samples studied, which, as stated before, could be triggering the expression of ALT-dependent pathways. 
In this study, we conducted a genomic analysis of 411 TM genes in 31 PCA studies and with the aid of different in-silico approaches, we proposed 20 candidate genes that are highly mutated as well as up and down regulated in different cancer types, which can be useful for future studies as potential molecular targets for the detection and understanding of the ALT pathway. Additionally, based on the prevalence of ALT+ tumors reported in this study, we strongly suggest to expand the study of ALT to a wide group of cancer types. Finally, we showed the need of a deep study of expression profiles and ex vivo assays to target TM genes that can help to understand the up and down regulation of ALT-related pathways and can provide guidance in the development of new therapies for the treatment of ALT+ tumors. We strongly believe this new decade will be promising for the study and understanding of this mechanism.

Supplementary Materials: The following are available online at http://www.mdpi.com/2073-4425/11/7/834/s1, Table S1. Gene set. Gene set of TM maintenance genes related to ALT used in this study, Table S2. Genomic alterations. Total genetic alterations normalized by the number of samples observed in the 31 Pan-Cancer Atlas studies for the 411 TM genes, Table S3. Cancer stages. Number of genetic alterations normalized by the number of samples in each stage of the Pan-Cancer studies available, Table S4. Genomic alterations in PCA studies. Frequency means of genomics alterations for each of the 411 TM genes and the 31 Pan-Cancer Atlas studies, Table S5. Enrichment analysis. Enrichment analysis detailed results from g:Profiler, Table S6. TM genes classification in different groups of ALT tumors.

Author Contributions: Conceptualization and methodology I.A.-C. and A.L.-C.; data curation, writing-original draft preparation, I.A.-C.; supervision, S.G. and C.P.-y.-M.; writing-review and editing, A.L.-C., J.G.-C., P.G.-R., P.E.L., A.P.-V., V.Y., A.K.Z. and S.G. All authors have read and agreed to the published version of the manuscript.

Funding: This research received no external funding

Acknowledgments: We like to thank to Universidad UTE research department for the continuous support in the development of these kind of researches.

Conflicts of Interest: The authors declare no conflict of interest.

\section{References}

1. Sommer, A.; Royle, N.J. ALT: A Multi-Faceted Phenomenon. Genes 2020, 11, 133. [CrossRef] [PubMed]

2. Hoang, S.M.; O'Sullivan, R.J. Alternative Lengthening of Telomeres: Building Bridges to Connect Chromosome Ends. Trends Cancer 2020, 6, 247-260. [CrossRef]

3. Recagni, M.; Bidzinska, J.; Zaffaroni, N.; Folini, M. The Role of Alternative Lengthening of Telomeres Mechanism in Cancer: Translational and Therapeutic Implications. Cancers 2020, 12, 949. [CrossRef]

4. de Lange, T. How telomeres solve the end-protection problem. Science 2009, 326, 948-952. [CrossRef] [PubMed]

5. Turner, K.J.; Vasu, V.; Griffin, D.K. Telomere Biology and Human Phenotype. Cells 2019, 8, 73. [CrossRef]

6. De Vitis, M.; Berardinelli, F.; Sgura, A. Telomere length maintenance in cancer: At the crossroad between telomerase and alternative lengthening of telomeres (ALT). Int. J. Mol. Sci. 2018, 19, 606. [CrossRef] [PubMed]

7. Zhang, J.M.; Yadav, T.; Ouyang, J.; Lan, L.; Zou, L. Alternative Lengthening of Telomeres through Two Distinct Break-Induced Replication Pathways. Cell Rep. 2019, 26, 955-968.e3. [CrossRef] [PubMed]

8. Heaphy, C.M.; Subhawong, A.P.; Hong, S.M.; Goggins, M.G.; Montgomery, E.A.; Gabrielson, E.; Netto, G.J.; Epstein, J.I.; Lotan, T.L.; Westra, W.H.; et al. Prevalence of the alternative lengthening of telomeres telomere maintenance mechanism in human cancer subtypes. Am. J. Pathol. 2011, 179, 1608-1615. [CrossRef]

9. Lee, M.; Teber, E.T.; Holmes, O.; Nones, K.; Patch, A.-M.; Dagg, R.A.; Lau, L.M.S.; Lee, J.H.; Napier, C.E.; Arthur, J.W.; et al. Telomere sequence content can be used to determine ALT activity in tumours. Nucleic Acids Res. 2018, 46, 4903-4918. [CrossRef]

10. Lovejoy, C.A.; Takai, K.; Huh, M.S.; Picketts, D.J.; de Lange, T. ATRX affects the repair of telomeric DSBs by promoting cohesion and a DAXX-dependent activity. PLoS Biol. 2020, 18, e3000594. [CrossRef]

11. Cox, K.E.; Maréchal, A.; Flynn, R.L. SMARCAL1 Resolves Replication Stress at ALT Telomeres. Cell Rep. 2016, 14, 1032-1040. [CrossRef] [PubMed]

12. Zhang, J.-M.; Zou, L. Alternative lengthening of telomeres: From molecular mechanisms to therapeutic outlooks. Cell Biosci. 2020, 10, 1-9. [CrossRef] [PubMed] 
13. Cesare, A.J.; Reddel, R.R. Alternative lengthening of telomeres: Models, mechanisms and implications. Nat. Rev. Genet. 2010, 11, 319-330. [CrossRef]

14. Lawlor, R.T.; Veronese, N.; Pea, A.; Nottegar, A.; Smith, L.; Pilati, C.; Demurtas, J.; Fassan, M.; Cheng, L.; Luchini, C.; et al. Alternative lengthening of telomeres (ALT) influences survival in soft tissue sarcomas: A systematic review with meta-analysis. BMC Cancer 2019, 19, 1-7. [CrossRef] [PubMed]

15. Hu, Y.; Shi, G.; Zhang, L.; Li, F.; Jiang, Y.; Jiang, S.; Ma, W.; Zhao, Y.; Songyang, Z.; Huang, J.; et al. Switch telomerase to ALT mechanism by inducing telomeric DNA damages and dysfunction of ATRX and DAXX. Sci. Rep. 2016, 6, 32280. [CrossRef]

16. Kumar, M.; Lechel, A.; Gunes, C. Telomerase: The Devil Inside. Genes 2016, 7, 43. [CrossRef]

17. Brosnan-Cashman, J.A.; Yuan, M.; Graham, M.K.; Rizzo, A.J.; Myers, K.M.; Davis, C.; Zhang, R.; Esopi, D.M.; Raabe, E.H.; Eberhart, C.G.; et al. ATRX loss induces multiple hallmarks of the alternative lengthening of telomeres (ALT) phenotype in human glioma cell lines in a cell line-specific manner. PLoS ONE 2018, 13, e0204159. [CrossRef]

18. Singhi, A.D.; Liu, T.-C.; Roncaioli, J.L.; Cao, D.; Zeh, H.J.; Zureikat, A.H.; Tsung, A.; Marsh, J.W.; Lee, K.K.; Hogg, M.E.; et al. Alternative Lengthening of Telomeres and Loss of DAXX/ATRX Expression Predicts Metastatic Disease and Poor Survival in Patients with Pancreatic Neuroendocrine Tumors. Clin. Cancer Res. 2017, 23, 600-609. [CrossRef]

19. Braun, D.M.; Chung, I.; Kepper, N.; Deeg, K.I.; Rippe, K. TelNet-A database for human and yeast genes involved in telomere maintenance. BMC Genet. 2018, 19, 32. [CrossRef]

20. Gao, J.; Aksoy, B.B.A.; Dogrusoz, U.; Dresdner, G.; Gross, B.; Sumer, S.O.; Sun, Y.; Jacobsen, A.; Sinha, R.; Larsson, E.; et al. Integrative analysis of complex cancer genomics and clinical profiles using the cBioPortal. Sci. Signal. 2013, 6, pl1.

21. Cerami, E.; Gao, J.; Dogrusoz, U.; Gross, B.E.; Sumer, S.O.; Aksoy, B.A.; Jacobsen, A.; Byrne, C.J.; Heuer, M.L.; Larsson, E.; et al. The cBio Cancer Genomics Portal: An Open Platform for Exploring Multidimensional Cancer Genomics Data: Figure 1. Cancer Discov. 2012, 2, 401-404. [CrossRef]

22. Hoadley, K.A.; Yau, C.; Hinoue, T.; Wolf, D.M.; Lazar, A.J.; Drill, E.; Shen, R.; Taylor, A.M.; Cherniack, A.D.; Thorsson, V.; et al. Cell-of-Origin Patterns Dominate the Molecular Classification of 10,000 Tumors from 33 Types of Cancer. Cell 2018, 173, 291-304.e6. [CrossRef] [PubMed]

23. Berger, A.C.; Korkut, A.; Kanchi, R.S.; Hegde, A.M.; Lenoir, W.; Liu, W.; Liu, Y.; Fan, H.; Shen, H.; Ravikumar, V.; et al. A Comprehensive Pan-Cancer Molecular Study of Gynecologic and Breast Cancers. Cancer Cell 2018, 33, 690-705.e9. [CrossRef] [PubMed]

24. Liu, Y.; Sethi, N.S.; Hinoue, T.; Schneider, B.G.; Cherniack, A.D.; Sanchez-Vega, F.; Seoane, J.A.; Farshidfar, F.; Bowlby, R.; Islam, M.; et al. Comparative Molecular Analysis of Gastrointestinal Adenocarcinomas. Cancer Cell 2018, 33, 721-735.e8. [CrossRef] [PubMed]

25. Campbell, J.D.; Yau, C.; Bowlby, R.; Liu, Y.; Brennan, K.; Fan, H.; Taylor, A.M.; Wang, C.; Walter, V.; Akbani, R.; et al. Genomic, Pathway Network, and Immunologic Features Distinguishing Squamous Carcinomas. Cell Rep. 2018, 23, 194-212.e6. [CrossRef]

26. Ricketts, C.J.; De Cubas, A.A.; Fan, H.; Smith, C.C.; Lang, M.; Reznik, E.; Bowlby, R.; Gibb, E.A.; Akbani, R.; Beroukhim, R.; et al. The Cancer Genome Atlas Comprehensive Molecular Characterization of Renal Cell Carcinoma. Cell Rep. 2018, 23, 313-326.e5. [CrossRef]

27. Huang, K.L.; Mashl, R.J.; Wu, Y.; Ritter, D.I.; Wang, J.; Oh, C.; Paczkowska, M.; Reynolds, S.; Wyczalkowski, M.A.; Oak, N.; et al. Pathogenic Germline Variants in 10,389 Adult Cancers. Cell 2018, 173, 355-370.e14. [PubMed]

28. Bailey, M.H.; Tokheim, C.; Porta-Pardo, E.; Sengupta, S.; Bertrand, D.; Weerasinghe, A.; Colaprico, A.; Wendl, M.C.; Kim, J.; Reardon, B.; et al. Comprehensive Characterization of Cancer Driver Genes and Mutations. Cell 2018, 173, 371-385.e18. [CrossRef] [PubMed]

29. Gao, Q.; Liang, W.-W.; Foltz, S.M.; Mutharasu, G.; Jayasinghe, R.G.; Cao, S.; Liao, W.-W.; Reynolds, S.M.; Wyczalkowski, M.A.; Yao, L.; et al. Driver Fusions and Their Implications in the Development and Treatment of Human Cancers. Cell Rep. 2018, 23, 227-238.e3. [CrossRef] [PubMed]

30. Liu, J.; Lichtenberg, T.; Hoadley, K.A.; Poisson, L.M.; Lazar, A.J.; Cherniack, A.D.; Kovatich, A.J.; Benz, C.C.; Levine, D.A.; Lee, A.V.; et al. An Integrated TCGA Pan-Cancer Clinical Data Resource to Drive High-Quality Survival Outcome Analytics. Cell 2018, 173, 400-416.e11. [CrossRef] [PubMed] 
31. Sanchez-Vega, F.; Mina, M.; Armenia, J.; Chatila, W.K.; Luna, A.; La, K.C.; Dimitriadoy, S.; Liu, D.L.; Kantheti, H.S.; Saghafinia, S.; et al. Oncogenic Signaling Pathways in The Cancer Genome Atlas. Cell 2018, 173, 321-337.e10. [CrossRef] [PubMed]

32. Szklarczyk, D.; Franceschini, A.; Wyder, S.; Forslund, K.; Heller, D.; Huerta-Cepas, J.; Simonovic, M.; Roth, A.; Santos, A.; Tsafou, K.P.; et al. STRING v10: Protein-protein interaction networks, integrated over the tree of life. Nucleic Acids Res. 2015, 43, D447-D452. [CrossRef] [PubMed]

33. Guerrero, S.; López-Cortés, A.; García-Cárdenas, J.M.; Armendáriz-Castillo, I.; Zambrano, A.K.; Indacochea, A.; Pérez-Villa, A.; Yumiceba, V.; Guevara-Ramírez, P.; Jacome-Alvarado, A.; et al. In silico analyses reveal new putative Breast Cancer RNA-binding proteins. BioRxiv 2020. [CrossRef]

34. Malkova, A.; Ira, G. Break-induced replication: Functions and molecular mechanism. Curr. Opin. Genet. Dev. 2013, 23, 271-279. [CrossRef] [PubMed]

35. KEGG Gene Set: KEGG_HOMOLOGOUS_RECOMBINATION. Available online: http://www.genome.jp/ $\mathrm{kegg} /$ pathway/hsa/hsa03440.html (accessed on 30 June 2020).

36. López-Cortés, A.; Paz-y-Miño, C.; Guerrero, S.; Cabrera-Andrade, A.; Barigye, S.J.; Munteanu, C.R.; González-Díaz, H.; Pazos, A.; Pérez-Castillo, Y.; Tejera, E.; et al. OncoOmics approaches to reveal essential genes in breast cancer: A panoramic view from pathogenesis to precision medicine. Sci. Rep. 2020, 10, 1-21. [CrossRef]

37. Raudvere, U.; Kolberg, L.; Kuzmin, I.; Arak, T.; Adler, P.; Peterson, H.; Vilo, J. g: Profiler: A web server for functional enrichment analysis and conversions of gene lists (2019 update). Nucleic Acids Res. 2019, 47, W191-W198. [CrossRef] [PubMed]

38. López-Cortés, A.; Guevara-Ramírez, P.; Guerrero, S.; Ortiz-Prado, E.; García-Cárdenas, J.M.; Zambrano, A.K.; Armendáriz-Castillo, I.; Pérez-Villa, A.; Yumiceba, V.; Varela, N.; et al. Metastatic signaling of hypoxia-related genes across TCGA Pan-Cancer types. BioRxiv 2020. [CrossRef]

39. Pompili, L.; Leonetti, C.; Biroccio, A.; Salvati, E. Diagnosis and treatment of ALT tumors: Is Trabectedin a new therapeutic option? J. Exp. Clin. Cancer Res. 2017, 36, 1-10. [CrossRef]

40. Ramamoorthy, M.; Smith, S. Loss of ATRX Suppresses Resolution of Telomere Cohesion to Control Recombination in ALT Cancer Cells. Cancer Cell 2015, 28, 357-369. [CrossRef]

41. Dilley, R.L.; Greenberg, R.A. ALTernative Telomere Maintenance and Cancer. Trends Cancer 2015, 1, $145-156$. [CrossRef] [PubMed]

42. Lovejoy, C.A.; Li, W.; Reisenweber, S.; Thongthip, S.; Bruno, J.; de Lange, T.; De, S.; Petrini, J.H.J.; Sung, P.A.; Jasin, M.; et al. Loss of ATRX, genome instability, and an altered DNA damage response are hallmarks of the alternative lengthening of Telomeres pathway. PLoS Genet. 2012, 8, 12-15. [CrossRef] [PubMed]

43. Nersisyan, L.; Hopp, L.; Loeffler-Wirth, H.; Galle, J.; Loeffler, M.; Arakelyan, A.; Binder, H. Telomere Length Maintenance and Its Transcriptional Regulation in Lynch Syndrome and Sporadic Colorectal Carcinoma. Front. Oncol. 2019, 9, 1172. [CrossRef]

44. Lafferty-Whyte, K.; Cairney, C.J.; Will, M.B.; Serakinci, N.; Daidone, M.-G.; Zaffaroni, N.; Bilsland, A.; Keith, W.N. A gene expression signature classifying telomerase and ALT immortalization reveals an hTERT regulatory network and suggests a mesenchymal stem cell origin for ALT. Oncogene 2009, 28, 3765-3774. [CrossRef] [PubMed]

45. Sobinoff, A.P.; Pickett, H.A. Mechanisms that drive telomere maintenance and recombination in human cancers. Curr. Opin. Genet. Dev. 2020, 60, 25-30. [CrossRef] [PubMed]

46. Lee, O.-H.; Kim, H.; He, Q.; Baek, H.J.; Yang, D.; Chen, L.-Y.; Liang, J.; Chae, H.K.; Safari, A.; Liu, D.; et al. Genome-wide YFP fluorescence complementation screen identifies new regulators for telomere signaling in human cells. Mol. Cell. Proteom. 2011, 10. [CrossRef] [PubMed]

47. Bryan, T.M.; Englezou, A.; Dalla-Pozza, L.; Dunham, M.A.; Reddel, R.R. Evidence for an alternative mechanism for maintaining telomere length in human tumors and tumor-derived cell lines. Nat. Med. 1997, 3, 1271-1274. [CrossRef]

48. Omori, Y.; Nakayama, F.; Li, D.; Kanemitsu, K.; Semba, S.; Ito, A.; Yokozaki, H. Alternative lengthening of telomeres frequently occurs in mismatch repair system-deficient gastric carcinoma. Cancer Sci. 2009, 100, 413-418. [CrossRef]

49. Henson, J.D.; Lau, L.M.; Koch, S.; Martin La Rotta, N.; Dagg, R.A.; Reddel, R.R. The C-Circle Assay for alternative-lengthening-of-telomeres activity. Methods 2017, 114, 74-84. [CrossRef] 
50. Fogli, A.; Demattei, M.-V.; Corset, L.; Vaurs-Barriere, C.; Chautard, E.; Biau, J.; Kemeny, J.-L.; Godfraind, C.; Pereira, B.; Khalil, T.; et al. Detection of the alternative lengthening of telomeres pathway in malignant gliomas for improved molecular diagnosis. J. Neuro-Oncol. 2017, 135, 381-390. [CrossRef]

51. Schwartzentruber, J.; Korshunov, A.; Liu, X.-Y.; Jones, D.T.W.; Pfaff, E.; Jacob, K.; Sturm, D.; Fontebasso, A.M.; Quang, D.-A.K.; Tonjes, M.; et al. Driver mutations in histone H3.3 and chromatin remodelling genes in paediatric glioblastoma. Nature 2012, 482, 226-231. [CrossRef]

52. Guièze, R.; Pages, M.; Véronèse, L.; Combes, P.; Lemal, R.; Gay-Bellile, M.; Chauvet, M.; Callanan, M.; Kwiatkowski, F.; Pereira, B.; et al. Telomere status in chronic lymphocytic leukemia with TP53 disruption. Oncotarget 2016, 7, 56976-56985. [CrossRef] [PubMed]

53. Chung, I.; Leonhardt, H.; Rippe, K. De novo assembly of a PML nuclear subcompartment occurs through multiple pathways and induces telomere elongation. J. Cell Sci. 2011, 124, 3603-3618. [CrossRef] [PubMed]

54. Osterwald, S.; Deeg, K.I.; Chung, I.; Parisotto, D.; Worz, S.; Rohr, K.; Erfle, H.; Rippe, K. PML induces compaction, TRF2 depletion and DNA damage signaling at telomeres and promotes their alternative lengthening. J. Cell Sci. 2015, 128, 1887-1900. [CrossRef]

55. Gaspar, T.B.; Sá, A.; Lopes, J.M.; Sobrinho-Simões, M.; Soares, P.; Vinagre, J. Telomere maintenance mechanisms in cancer. Genes 2018, 9, 241. [CrossRef]

56. Dejardin, J.; Kingston, R.E. Purification of proteins associated with specific genomic Loci. Cell 2009, 136, 175-186. [CrossRef] [PubMed]

57. Potts, P.R.; Yu, H. The SMC5/6 complex maintains telomere length in ALT cancer cells through SUMOylation of telomere-binding proteins. Nat. Struct. Mol. Biol. 2007, 14, 581-590. [CrossRef] [PubMed]

58. Gomez, D.E.; Armando, R.G.; Farina, H.G.; Menna, P.L.; Cerrudo, C.S.; Ghiringhelli, P.D.; Alonso, D.F. Telomere structure and telomerase in health and disease. Int. J. Oncol. 2012, 41, 1561-1569. [CrossRef]

59. Jiang, W.-Q.; Zhong, Z.-H.; Henson, J.D.; Neumann, A.A.; Chang, A.C.-M.; Reddel, R.R. Suppression of alternative lengthening of telomeres by Sp100-mediated sequestration of the MRE11/RAD50/NBS1 complex. Mol. Cell. Biol. 2005, 25, 2708-2721. [CrossRef]

60. Ramlee, M.K.; Wang, J.; Toh, W.X.; Li, S. Transcription Regulation of the Human Telomerase Reverse Transcriptase (hTERT) Gene. Genes 2016, 7, 50. [CrossRef]

61. Uziel, O.; Yosef, N.; Sharan, R.; Ruppin, E.; Kupiec, M.; Kushnir, M.; Beery, E.; Cohen-Diker, T.; Nordenberg, J.; Lahav, M.; et al. The effects of telomere shortening on cancer cells: A network model of proteomic and microRNA analysis. Genomics 2015, 105, 5-16. [CrossRef]

62. Tong, A.S.; Stern, J.L.; Sfeir, A.; Kartawinata, M.; de Lange, T.; Zhu, X.-D.; Bryan, T.M. ATM and ATR Signaling Regulate the Recruitment of Human Telomerase to Telomeres. Cell Rep. 2015, 13, 1633-1646. [CrossRef] [PubMed]

63. Grolimund, L.; Aeby, E.; Hamelin, R.; Armand, F.; Chiappe, D.; Moniatte, M.; Lingner, J. A quantitative telomeric chromatin isolation protocol identifies different telomeric states. Nat. Commun. 2013, 4, 1-12.

64. Lee, Y.-K.; Park, N.-H.; Lee, H. Prognostic value of alternative lengthening of telomeres-associated biomarkers in uterine sarcoma and uterine carcinosarcoma. Int. J. Gynecol. Cancer 2012, 22, 434-441. [CrossRef] [PubMed]

65. Ghosh, A.K.; Rossi, M.L.; Singh, D.K.; Dunn, C.; Ramamoorthy, M.; Croteau, D.L.; Liu, Y.; Bohr, V.A. RECQL4, the protein mutated in Rothmund-Thomson syndrome, functions in telomere maintenance. J. Biol. Chem. 2012, 287, 196-209. [CrossRef]

66. Cerone, M.A.; Burgess, D.J.; Naceur-Lombardelli, C.; Lord, C.J.; Ashworth, A. High-throughput RNAi screening reveals novel regulators of telomerase. Cancer Res. 2011, 71, 3328-3340. [CrossRef]

67. Zaboikin, M.; Zaboikina, T.; Freter, C.; Srinivasakumar, N. Non-Homologous End Joining and Homology Directed DNA Repair Frequency of Double-Stranded Breaks Introduced by Genome Editing Reagents. PLoS ONE 2017, 12, e0169931. [CrossRef]

68. Kent, T.; Gracias, D.; Shepherd, S.; Clynes, D. Alternative Lengthening of Telomeres in Pediatric Cancer: Mechanisms to Therapies. Front. Oncol. 2020, 9, 1518. [CrossRef]

69. Hyman, E.; Kauraniemi, P.; Hautaniemi, S.; Wolf, M.; Mousses, S.; Rozenblum, E.; Ringnér, M.; Sauter, G.; Monni, O.; Elkahloun, A.; et al. Impact of DNA amplification on gene expression patterns in breast cancer. Cancer Res. 2002, 62, 6240-6245. 
70. Albertson, D.G. Gene amplification in cancer. Trends Genet. 2006, 22, 447-455. [CrossRef]

71. García-Cárdenas, J.M.; Guerrero, S.; López-Cortés, A.; Armendáriz-Castillo, I.; Guevara-Ramírez, P.; Pérez-Villa, A.; Yumiceba, V.; Zambrano, A.K.; Leone, P.E.; Paz-y-Miño, C.; et al. Post-transcriptional Regulation of Colorectal Cancer: A Focus on RNA-Binding Proteins. Front. Mol. Biosci. 2019, 6, 65. [CrossRef] 